\title{
Características de pesquisas nacionais e internacionais sobre temas controversos na Educação Científica
}

\section{The characteristics of national and international research on controversial themes in Science Education}

\author{
Kellys Regina Rodio Saucedo ${ }^{1}$. https://orcid.org/0000-0002-8703-7388 \\ Maurício Pietrocola ${ }^{1} \cdot$ https://orcid.org/0000-0003-1839-8005
}

\begin{abstract}
Resumo: Nessa pesquisa analisamos os perfis qualitativos de pesquisas nacionais e internacionais sobre temas controversos na produção em Educação Científica. Em termos metodológicos exploramos 120 publicações, na íntegra, originadas da consulta às Atas das edições do Encontro Nacional de Pesquisa em Educação em Ciências (ENPEC) e à biblioteca virtual Education Resources Information Center (ERIC). Os resultados da investigação nos indicaram uma lacuna preocupante na produção do conhecimento relativo ao Ensino Fundamental, sobretudo nos anos iniciais em ambos os perfis, e a concentração das controvérsias em tópicos da área da Biologia, se comparada às áreas de Física e Química. Destacamos, ainda, a emergência de uma nova perspectiva de análise com foco nas emoções, em um conjunto de artigos de âmbito internacional, que pode, também, vir a constituir um quadro de interesse para futuras pesquisas acadêmicas nacionais.
\end{abstract}

Palavras-chave: Educação científica. Ensino fundamental. CTS. Pesquisa científica. Produção científica.

\begin{abstract}
In this paper, we analyze the qualitative databases of national and international research on controversial themes in Science Education. In methodological terms, we carefully examined 120 scientific publications by accessing the Proceedings of the editions of Encontro Nacional de Pesquisa em Educação em Ciências (ENPEC) (National Meeting of Research in Science Education) and the files of the Education Resources Information Center (ERIC). The research results indicated a disquieting gap in the production of knowledge related to Elementary Education, especially concerning the early years in both databases, as well as the concentration of controversies on topics in the area of Biology when compared to the areas of Physics and Chemistry. We also highlight the emergence of a new perspective of analysis, focusing on emotions, in a number of international papers, which may also constitute an issue of interest to national academic research in the future.
\end{abstract}

Keywords: Science education. Basic education. STS. Scientific research. Scientific production.

\footnotetext{
${ }^{1}$ Universidade de São Paulo (USP), Faculdade de Educação (FE), São Paulo, SP, Brasil. E-mail: kellys@usp.br 


\title{
Introdução
}

$\mathrm{Na}$ pesquisa internacional em Educação Científica os temas controversos sociocientíficos estão cada vez mais presentes. De acordo com Levinson (2006), inicialmente os temas controversos tinham um cunho mais social do que científico e tecnológico e eram voltados à abordagem de relações familiares, questões étnicas e desigualdades sociais, por exemplo. Nos anos de 1980, as controvérsias associadas às implicações de natureza social, científica e tecnológica ganharam destaque no contexto escolar. Nas décadas seguintes, o movimento Ciência, Tecnologia e Sociedade (CTS) revigorou-se como linha de pesquisa e possibilidade de renovação curricular, com o objetivo de melhorar a compreensão pública da Ciência e o posicionamento de estudantes frente a polêmicas reais, internas e externas, do progresso científico e tecnológico. Atualmente,

\begin{abstract}
As chamadas questões sociocientíficas controversas (QSC), questões sociocientíficas, temas sociocientíficos, temas controversos, temas polêmicos ou temas contemporâneos são uma parte de uma ampla variedade de perspectivas da abordagem Ciência, Tecnologia e Sociedade (CTS) originada na área da Educação em Ciências (SCHNEIDER-FELICIO, 2016, p. 6).
\end{abstract}

Na produção científica, os termos destacados acima têm sido frequentemente utilizados para “[...] designar questões em comum” (DUSSO, 2015, p. 36) ${ }^{2}$. Entre autores brasileiros existe o consenso de que as controvérsias científicas envolvem questões polêmicas ligadas a enfrentamentos éticos, morais, valorativos e sociais, em que diferentes pontos de vista são mobilizados para além da Ciência (VARGAS; MARTÍNEZ-PÉREZ, 2011; AZEVEDO et al., 2013).

No Brasil, a pesquisa envolvendo a temática CTS e as questões controversas é bem mais recente e somente a partir da década de 1990 é que os Programas de Pós-Graduação apresentaram seus primeiros estudos (SANTOS, 2008). Lima e Martins (2013), investigando periódicos nacionais, concluíram que as publicações a esse respeito eram menos expressivas do que a produção internacional. Sousa e Gehlen (2017), com o objetivo de identificar a compreensão dos pesquisadores brasileiros quanto à natureza das questões sociocientíficas analisaram trabalhos publicados no Encontro Nacional de Pesquisa em Educação em Ciências (ENPEC). Esses autores, por fim, não identificaram evidências suficientemente claras para definir se as questões, na pesquisa nacional, são entendidas como “[...] recurso didático-pedagógico, objeto de aprendizagem em sala de aula ou elemento estruturante do currículo" (SOUSA; GEHLEN, 2017, p. 1).

No contexto educacional, a abordagem de temáticas controversas em Ciência, Tecnologia, Sociedade e Ambiente (CTSA) como eixo da Alfabetização Científica, têm apresentado

\footnotetext{
${ }^{2}$ Diante dessa diversidade de termos, apesar de possuírem natureza distinta, adotaremos tema(s) controverso(s) para designar as pesquisas associadas a controvérsias no ensino de Ciências em geral, sejam sociais, científicas, tecnológicas ou ambientais. Manteremos, no entanto, na análise dos trabalhos do ENPEC e dos artigos da ERIC o termo utilizado na publicação original pelos autores.
} 
desdobramentos em diferentes vertentes, como: na organização do currículo escolar, nas metodologias do ensino e na formação inicial e continuada de professores de Ciências. (KOKSAL; CAKIROGLU; GEBAN, 2016; MARTÍNEZ-PEREZ, 2012; SILVA, 2016). A intensificação das pesquisas sobre temas controversos e seus desdobramentos indicam a necessidade de uma caracterização mais geral, que explicite o perfil qualitativo da produção acadêmica, e que venha relacionada à pesquisa internacional. Com esse escopo empreendemos duas frentes de consulta à produção acadêmica: prioritariamente, na plataforma Education Resources Information Center $(\text { ERIC })^{3}$ e, complementarmente, nas atas das edições do Encontro Nacional de Pesquisa em Educação em Ciências (ENPEC) ${ }^{4}$.

Analisamos as publicações da ERIC e do ENPEC com o objetivo de responder às seguintes questões: (i) quais são os temas controversos abordados com maior frequência nas pesquisas em ensino de Ciências?; (ii) quais as principais reflexões empreendidas pelos pesquisadores?; (iii) que tipos de pesquisa e procedimentos de análise de dados vêm sendo priorizados nessas investigações?; e, (iv) em que níveis educacionais e sob quais sujeitos se concentram as pesquisas?

Os resultados dessa investigação, que apontam para um novo foco e novas técnicas de análise de dados nos periódicos internacionais, que podem vir a constituir um quadro de interesse à produção acadêmica nacional, virão explicitados nas próximas seções deste artigo.

\section{Percurso metodológico}

As orientações de Romanowski e Ens (2006) para a modalidade de pesquisa do tipo estado do conbecimento foram aqui consideradas. Os dados obtidos por meio do estado do conhecimento, segundo a autora, apontam para o objeto de atenção dos pesquisadores quanto à temática, aos subtemas e aos tópicos priorizados, revelando aspectos pouco explorados, e dando indicação também sobre as perspectivas teóricas, os instrumentos, os métodos, a orientação para a formulação das categorias de análise, entre outros aspectos relevantes da pesquisa.

Como mencionado anteriormente, duas bases foram consultadas: a Education Resources Information Center (ERIC), e as Atas das edições do Encontro Nacional de Pesquisa em Educação em Ciências (ENPEC). A ERIC iniciou oficialmente suas atividades em 1964, patrocinada pelo Instituto de Ciências da Educação do Departamento de Educação dos Estados Unidos. É uma das maiores bibliotecas on-line de pesquisa e informação educacional. Em 2016, os seus registros, que são submetidos a uma rigorosa política de seleção, ultrapassaram 1,6 milhões, entre periódicos, Atas de conferências, teses, dissertações e outras modalidades de divulgação de pesquisa. Isso faz da ERIC uma das principais fontes de pesquisa educacional, devido a um vasto e diversificado banco de dados, que é atualizado semestralmente.

No Brasil, optamos pelas Atas do ENPEC como fonte de pesquisa devido à ausência de uma plataforma on-line semelhante às características e aos recursos de pesquisa oferecidos

\footnotetext{
${ }^{3}$ Disponível em: https://eric.ed.gov/. Acesso em: 21 dez. 2016.

${ }^{4}$ Disponível em: http://abrapecnet.org.br/wordpress/pt/atas-dos-enpecs/. Acesso em: 21 fev. 2019.
} 
pela ERIC na área educacional e também pelo baixo índice de trabalhos nacionais indexados no exterior, mais especificamente na área de Educação Científica. O ENPEC é um evento de abrangência nacional e ocorrência bienal, organizado pela Associação Brasileira de Pesquisa em Educação em Ciências (ABRAPEC), que objetiva favorecer a interação entre os pesquisadores das áreas de Ensino de Física, de Biologia, de Química, de Geociências, de Ambiente, de Saúde e outras afins.

A opção pelo ENPEC é justificada, ainda: (i) por sua representatividade na comunidade acadêmica; (ii) pela seriedade dos critérios científicos arrolados na avaliação dos trabalhos; (iii) porque grande parte dos trabalhos socializados no ENPEC integram a produção dos principais periódicos nacionais e das pesquisas desenvolvidas ou em desenvolvimento nos Programas de Pós-Graduação da área de Educação Científica.

Para o presente trabalho, em termos metodológicos, todas as 120 publicações, 46 originadas da consulta às Atas das edições do ENPEC, e 74 resultantes da busca na base ERIC, foram lidas na íntegra, categorizadas e analisadas em busca de um reconhecimento quanto aos temas abordados, às reflexões empreendidas, às opções metodológicas das pesquisas, e aos sujeitos e níveis educacionais considerados nos estudos.

O período selecionado para a composição do estado do conhecimento em relação aos trabalhos divulgados no ENPEC compreende os biênios entre 1997 (primeira edição do evento) e $2013^{5}$. Utilizamos a ferramenta de busca on-line dos trabalhos, nas Atas dos eventos, a partir dos termos: (i) controvérsia; (ii) sociocientífico/a; (iii) sócio-científico $/ \mathrm{a}^{6}$; (iv) controverso/a.

Nesse período identificamos 46 trabalhos, de um total de 5.436 trabalhos apresentados entre comunicações orais e painéis ${ }^{7}$. A maior parte dessas pesquisas, equivalente a $68 \%$ dos 46 trabalhos, concentra-se nos anos de 2011 e 2013, sendo que, no encontro de 2011, pesquisadores brasileiros e colombianos organizaram um Simpósio, intitulado: $A$ abordagem de questões sociocientíficas no ensino de ciências: contribuições à pesquisa da área.

Os 46 trabalhos foram codificados com as iniciais AEN, que remetem às iniciais de artigo e encontro, acompanhadas de uma sequência numérica, respeitando a ordem cronológica de publicação e as normas da Associação Brasileira de Normas Técnicas (2002) para referências bibliográficas. O Quadro 1 apresenta exemplos dessa organização.

\footnotetext{
${ }^{5}$ A título de explicação, informamos que este ano não é o da última edição do ENPEC, mas, sim, o da disponibilização das Atas eletrônicas quando realizado o levantamento de dados em março de 2017.

${ }^{6}$ Até 2009, a grafia oficial era sócio-científico. A partir desse ano passou a ser sociocientífico.

${ }^{7}$ Inicialmente, o levantamento foi concentrado somente nas comunicações orais. Entretanto, nas edições de 2011 e 2013, a ferramenta de busca não apresenta opção para a distinção entre comunicação oral e painel, o que nos levou a considerar as duas modalidades de apresentação no período em destaque. Isso influenciou no resultado mais expressivo das publicações sobre o tema no período, assim como a realização de um simpósio direcionado tematicamente às controvérsias em 2011.
} 
Quadro 1 - Exemplificação de codificação dos artigos publicados no ENPEC (1997-2013)

\begin{tabular}{|c|c|l|}
\hline Código & Ano & \multicolumn{1}{c|}{ Referência } \\
\hline AEN1 2001 & $\begin{array}{l}\text { SANTOS, W. L. P.; MORTIMER, E. F.; SCOTT, P. H. A argumentação } \\
\text { em discussões sócio-científicas: reflexões a partir de um estudo de caso. } \\
\text { In: ENCONTRO NACIONAL DE PESQUISA EM EDUCAÇÃO EM } \\
\text { CIÊNCIAS, 3., 2001, Águas de Lindóia. Anais [...]. Águas de Lindóia: } \\
\text { ABRAPEC, 2001. p. 1-12. }\end{array}$ \\
\hline AEN2 2003 & $\begin{array}{l}\text { AULER, D.; DELIZOICOV, D. Ciência-tecnologia-sociedade: relações } \\
\text { estabelecidas por professores de ciências. In: ENCONTRO NACIONAL DE } \\
\text { PESQUISA EM EDUCAÇÃO EM CIÊNCIAS, 4., 2003, Bauru. Anais [...]. } \\
\text { Bauru: ABRAPEC, 2003. p. 1-13. }\end{array}$ \\
\hline AEN3 & 2003 & $\begin{array}{l}\text { FÁVARO; R. D. et al. Engenharia genética e biologia molecular: } \\
\text { possibilidades e limites do trabalho do professor de biologia do ensino médio. } \\
\text { In: ENCONTRO NACIONAL DE PESQUISA EM EDUCAÇÃO EM } \\
\text { CIÊNCIAS, 4., 2003, Bauru. Anais [.... Bauru: ABRAPEC, 2003. p. 1-11. }\end{array}$ \\
\hline
\end{tabular}

Fonte: elaborado pelos autores.

Na sequência realizamos a pré-análise dos trabalhos que contribuíram para sistematização do Quadro 2, abaixo exemplificado, seguindo os objetivos definidos para o levantamento de dados.

Quadro 2 - Exemplificação dos tópicos analisados nos artigos publicados no ENPEC

\begin{tabular}{|c|c|c|c|c|c|}
\hline Referência & $\begin{array}{c}\text { Temas } \\
\text { controversos }\end{array}$ & $\begin{array}{c}\text { Reflexões } \\
\text { empreendidas }\end{array}$ & $\begin{array}{l}\text { Tipo de } \\
\text { pesquisa }\end{array}$ & $\begin{array}{c}\text { Procedimentos } \\
\text { e análise de } \\
\text { dados }\end{array}$ & $\begin{array}{l}\text { Sujeitos } \\
\text { da } \\
\text { Pesquisa }\end{array}$ \\
\hline $\begin{array}{l}\text { SANTOS, W. L. P.; } \\
\text { MORTIMER, E. } \\
\text { F.; SCOTT, P. H. A } \\
\text { argumentação em } \\
\text { discussões sócio- } \\
\text { científicas: reflexões a } \\
\text { partir de um estudo de } \\
\text { caso. In: ENCONTRO } \\
\text { NACIONAL DE } \\
\text { PESQUISA EM } \\
\text { EDUCAÇÃO EM } \\
\text { CIÊNCIAS, 3., 2001, } \\
\text { Águas de Lindóia. Anais } \\
\text { [...]. Águas de Lindóia: } \\
\text { ABRAPEC, 2001. p. 1-12. }\end{array}$ & $\begin{array}{l}\text { Lixo, resíduos } \\
\text { sólidos, } \\
\text { ciência, } \\
\text { religião e } \\
\text { magia. }\end{array}$ & $\begin{array}{l}\text { Intervenções } \\
\text { pedagógicas } \\
\text { e discurso } \\
\text { argumentativo. }\end{array}$ & $\begin{array}{l}\text { Estudo de } \\
\text { caso. }\end{array}$ & $\begin{array}{l}\text { Análise } \\
\text { discursiva das } \\
\text { narrativas de } \\
\text { ensino. Padrão } \\
\text { IRF }\end{array}$ & $\begin{array}{l}\text { Estudantes } \\
\text { do Ensino } \\
\text { Médio e } \\
\text { professor } \\
\text { de } \\
\text { Química }\end{array}$ \\
\hline
\end{tabular}


Quadro 2 - continuação

\begin{tabular}{|c|c|c|c|c|c|}
\hline Referência & $\begin{array}{c}\text { Temas } \\
\text { controversos }\end{array}$ & $\begin{array}{c}\text { Reflexões } \\
\text { empreendidas }\end{array}$ & $\begin{array}{l}\text { Tipo de } \\
\text { pesquisa }\end{array}$ & $\begin{array}{l}\text { Procedimentos } \\
\text { e análise de } \\
\text { dados }\end{array}$ & $\begin{array}{c}\text { Sujeitos } \\
\text { da } \\
\text { Pesquisa }\end{array}$ \\
\hline $\begin{array}{l}\text { AULER, D.; } \\
\text { DELIZOICOV, D. } \\
\text { Ciência-tecnologia- } \\
\text { sociedade: relações } \\
\text { estabelecidas por } \\
\text { professores de ciências. } \\
\text { In: ENCONTRO } \\
\text { NACIONAL DE } \\
\text { PESQUISA EM } \\
\text { EDUCAÇÃO EM } \\
\text { CIÊNCIAS, 4., 2003, } \\
\text { Bauru. Anais [...]. Bauru: } \\
\text { ABRAPEC, 2003. p. 1-13. }\end{array}$ & $\begin{array}{l}\text { Manipulação } \\
\text { genética, } \\
\text { clonagem, } \\
\text { produção e } \\
\text { distribuição } \\
\text { de alimentos, } \\
\text { crise } \\
\text { energética. }\end{array}$ & $\begin{array}{l}\text { Compreensão } \\
\text { de professores } \\
\text { sobre } \\
\text { interações } \\
\text { entre CTS, } \\
\text { formação } \\
\text { docente inicial } \\
\text { e formação } \\
\text { docente } \\
\text { continuada. }\end{array}$ & $\begin{array}{l}\text { Pesquisa } \\
\text { de campo. }\end{array}$ & $\begin{array}{l}\text { Construção e } \\
\text { adaptação de } \\
\text { parâmetros } \\
\text { para a análise } \\
\text { de interações } \\
\text { entre CTS. } \\
\text { Instrumento } \\
\text { VOSTS }\end{array}$ & $\begin{array}{l}\text { Professores } \\
\text { de Ciências }\end{array}$ \\
\hline $\begin{array}{l}\text { FÁVARO, R. D. et al. } \\
\text { Engenharia genética } \\
\text { e biologia molecular: } \\
\text { possibilidades e limites } \\
\text { do trabalho do professor } \\
\text { de biologia do ensino } \\
\text { médio. In: ENCONTRO } \\
\text { NACIONAL DE } \\
\text { PESQUISA EM } \\
\text { EDUCAÇÃO EM } \\
\text { CIÊNCIAS, 4., 2003, } \\
\text { Bauru. Anais [...]. Bauru: } \\
\text { ABRAPEC, 2003. p. 1-11. }\end{array}$ & $\begin{array}{l}\text { Engenharia } \\
\text { genética. }\end{array}$ & $\begin{array}{l}\text { Recursos } \\
\text { didáticos, } \\
\text { material de } \\
\text { trabalho em } \\
\text { sala de aula } \\
\text { e fontes de } \\
\text { pesquisa do } \\
\text { professor. }\end{array}$ & $\begin{array}{l}\text { Pesquisa } \\
\text { de campo. }\end{array}$ & $\begin{array}{l}\text { Análise de } \\
\text { conteúdo. }\end{array}$ & $\begin{array}{l}\text { Professores } \\
\text { de Biologia } \\
\text { do Ensino } \\
\text { Médio. }\end{array}$ \\
\hline
\end{tabular}

Fonte: elaborado pelos autores.

Sobre o estado do conhecimento realizado na ERIC, esse teve, entre seus objetivos, além dos já descritos, o de explorar o cenário de pesquisa internacional. Inicialmente, foi importante identificarmos os termos associados à temática, para isso utilizamos o recurso de busca on-line oferecido pela ERIC, inserimos apenas: controversial e socioscientific issues, e, posteriormente, acrescentamos os indicados pela base: (i) controversial topics; (ii) controversial themes; e, (iii) controversial issues.

Com esse direcionamento foram computados 1.013 títulos nos últimos 20 anos. A respeito desse universo de títulos, como estratégia de refinamento dos dados, fizemos a opção por artigos científicos exclusivamente publicados em periódicos revisados, o que reduziu a amostra para 548 publicações. Realizamos um novo recorte temporal, entre 2007 e 2016, chegando a 290 artigos. Em nossa avaliação os 290 artigos correspondem a uma amostra repre- 
sentativa das pesquisas sobre os temas controversos ${ }^{8}$. Com isso, assim definido, realizamos a leitura dos resumos para identificar quais estavam relacionados especificamente aos temas controversos na Educação Científica. Dentre os 290 artigos, 216 deles faziam referência a controvérsias linguísticas, debates jurídicos, entre outros tópicos não associados à Educação Científica. Permaneceram apenas 74 artigos, que refletem nosso objeto de pesquisa e, por isso, foram igualmente lidos na integra, codificados pela sigla AER, da junção das iniciais de artigo e ERIC, seguida do número do artigo por ordem crescente da data de publicação.

Agrupamos, em outro momento, os trabalhos do ENPEC e os artigos da ERIC em seis novas categorias, conforme o Quadro 3. Elas são subcategorias construídas por meio de análise de conteúdo (BARDIN, 1995), a partir da categoria reflexões empreendidas (Quadro 2), que foi um dos pontos considerados nos objetivos da nossa pesquisa.

A análise de conteúdo consiste em: "[...] descobrir os núcleos de sentido que compõem a comunicação e cuja presença ou frequência de aparição pode significar alguma coisa para o objetivo analítico escolhido" (BARDIN, 1995, p. 105). A técnica da análise de conteúdo prevê a execução de três fases cronológicas, que foram devidamente percorridas: a pré-análise e a exploração do material - essas duas fases correspondem a um processo dinâmico de organização do conteúdo, a fim de que se evidenciem unidades em conjunto aos objetivos, levando à formação de indicadores, os quais são precursores das subcategorias - e a última fase, que é o tratamento dos resultados, referente à interpretação e análise temática, com vistas a discutir os resultados à luz dos significados atribuídos pelo autor. As categorias ficaram assim definidas:

Quadro 3 - Descrição das categorias de agrupamento frente à análise de conteúdo

\begin{tabular}{|l|l|}
\hline \multicolumn{1}{|c|}{ Categorias } & \multicolumn{1}{c|}{ Descrição } \\
\hline Metodologias do ensino & $\begin{array}{l}\text { Abordam as metodologias e as estratégias didático-pedagógicas aplicadas e outros } \\
\text { aspectos relativos ao estudo de temas controversos em sala de aula. }\end{array}$ \\
\hline $\begin{array}{l}\text { Processos de ensino e } \\
\text { de aprendizagem }\end{array}$ & $\begin{array}{l}\text { Apresentam reflexões sobre como os alunos adquirem, constroem, se apropriam ou } \\
\text { rejeitam conhecimentos ao lidarem com temas controversos. }\end{array}$ \\
\hline $\begin{array}{l}\text { Formação de } \\
\text { professores }\end{array}$ & $\begin{array}{l}\text { Problematizam a formação docente inicial e continuada dos professores e a abordagem } \\
\text { de temas controversos nas licenciaturas. }\end{array}$ \\
\hline Recursos didáticos & $\begin{array}{l}\text { Analisam a produção e o uso de materiais didáticos explicitamente direcionados aos } \\
\text { temas controversos. }\end{array}$ \\
\hline Estudos teóricos & $\begin{array}{l}\text { Realizam levantamento bibliográfico estabelecendo relações com contextos sociais e } \\
\text { históricos abordando os temas controversos na Educação Científica. }\end{array}$ \\
\hline Metaestudos & $\begin{array}{l}\text { Mapeiam a produção do conhecimento relacionada aos temas controversos na } \\
\text { Educação Científica, produzindo relações entre os materiais levantados e uma primeira } \\
\text { validação do quadro teórico sobre a temática. }\end{array}$ \\
\hline
\end{tabular}

Fonte: elaborado pelos autores.

${ }^{8}$ O último acesso à ERIC para obtenção de dados foi em janeiro de 2017. 


\section{O perfil das pesquisas nacionais}

Nas pesquisas sobre temas controversos na Educação Científica realizadas nas edições do ENPEC, os artigos que compõem os grupos (i) metodologias do ensino; (ii) processos de ensino e de aprendizagem; e, (iii) formação de professores concentram $63 \%$ dos trabalhos; os que desenvolveram ou analisaram (iv) materiais didáticos, 9\%; os (v) estudos teóricos; e, os (vi) metaestudos, juntos, somam $28 \%$ dessa fatia. Somente após essas etapas, descritas na metodologia, é que os artigos foram reorganizados como disposto no quadro abaixo:

Quadro 4 - Categorização das pesquisas nacionais sobre temas controversos

\begin{tabular}{|l|l|c|}
\hline \multicolumn{1}{|c|}{ Categorias } & \multicolumn{1}{|c|}{ Pesquisas } & \multicolumn{1}{|c|}{$\begin{array}{c}\text { Total por } \\
\text { categoria }\end{array}$} \\
\hline $\begin{array}{l}\text { Metodologias do } \\
\text { Ensino }\end{array}$ & $\begin{array}{l}\text { AEN1; AEN4; AEN11; AEN12; AEN15; AEN18; AEN22; } \\
\text { AEN27; AEN32; AEN36; AEN38; AEN41; AEN45. }\end{array}$ & 13 pesquisas. \\
\hline $\begin{array}{l}\text { Processos de ensino e } \\
\text { de aprendizagem }\end{array}$ & $\begin{array}{l}\text { AEN5; AEN6; AEN14; AEN20; AEN23; AEN24; AEN34; } \\
\text { AEN39. }\end{array}$ & 8 pesquisas. \\
\hline $\begin{array}{l}\text { Formação de } \\
\text { professores }\end{array}$ & $\begin{array}{l}\text { AEN2; AEN8; AEN16; AEN29; AEN30; AEN35; AEN40; } \\
\text { AEN42. }\end{array}$ & 8 pesquisas. \\
\hline Recursos didáticos & AEN3; AEN7; AEN9; AEN37. & 4 pesquisas. \\
\hline Estudos teóricos & $\begin{array}{l}\text { AEN13; AEN17; AEN19; AEN21; AEN26; AEN28; } \\
\text { AEN31; AEN43; AEN46. }\end{array}$ & 9 pesquisas. \\
\hline Metaestudos & AEN10; AEN25; AEN33; AEN44. & 4 pesquisas. \\
\hline
\end{tabular}

Fonte: elaborado pelos autores.

Em relação à primeira categoria, ela aborda as metodologias e estratégias didáticopedagógicas. Entre as reflexões empreendidas estão as estratégias discursivas realizadas pelos professores que priorizam o desenvolvimento argumentativo dos alunos (AEN1; AEN27).

Atividades como júri simulado, role playing game, notícias circuladas na mídia, projetos temáticos e as "ilhas de racionalidade" (FOUREZ, 1994) são algumas das ações empregadas em sala de aula para estimular a tomada de decisão e fomentar as reflexões entre professor-aluno, aluno-aluno.

Constituem, também, objeto de estudo, as estratégias discursivas assumidas por estudantes para administrar as relações entre o conhecimento científico e o conhecimento religioso (AEN4) e o estudo do raciocínio informal (AEN45). São analisadas, também, a produção de metodologias que avancem sobre o que ensinar? e o como ensinar? para a formação da atitude científica crítica dos estudantes em relação à influência da Ciência e da Tecnologia em sua vida cotidiana (AEN22, AEN36).

No trabalho AEN32 consta outro exemplo de como os assuntos controversos, abordados pelo viés estratégia de ensino, fundam os discursos dos estudantes, as marcas autorais e a capacidade de movimento produzida pelo discurso alheio. Alguns dos trabalhos, dessa 
categoria, também indicaram a importância de construir propostas metodológicas em que os temas sociocientíficos estejam inseridos por seu potencial para o favorecimento de construções verbais e para o estudo das interações (AEN11). De acordo com Mendes e Santos (2011, p. 1), a inserção desses tópicos no ensino vem com a orientação de não os considerar panaceias para o desenvolvimento de habilidades argumentativas, havendo a necessidade da "[...] articulação entre as dimensões social e científica e a incorporação dos elementos característicos da argumentação" para a sua efetivação (AEN18).

O que ficou evidenciado em relação às categorias analíticas aplicadas nesses trabalhos, é que a argumentação é o principal foco de estudo, sob a consideração de que esta, em sendo bem-sucedida, provoca os alunos para a formulação de posicionamentos próprios frente aos temas controversos sociocientíficos (AEN12, AEN38, AEN41), tendo como implicação aulas mais interativas e dialógicas (AEN15).

O segundo bloco categórico é o dos processos de ensino e de aprendizagem. Nesse bloco, a visão de Ciência como cultura e seus reflexos na comunicação e na Educação Científica, com destaque para aprendizagem de conteúdos e o desenvolvimento cognitivo dos alunos, compõe o trabalho AEN5. Os impasses ocasionados por elementos da cultura religiosa dos alunos, em controvérsias da biologia, também são temas de estudo (AEN6) e as aprendizagens individuais e coletivas no contexto dos movimentos sociais (AEN14).

A frequência com que os estudantes recuperam o conhecimento científico em situações de ensino de questões sociocientíficas está entre as observações realizadas nos trabalhos AEN20 e AEN24. Enquanto isso, AEN23 dá ênfase aos aspectos morais e éticos despertados nessa abordagem. As autoras de AEN34 dedicaram sua investigação a compreender como os alunos adquirem conhecimentos ao lidarem com questões sociocientíficas e a aplicação delas em suas vidas. Os graus de sensibilidade moral em situações que requerem dos alunos tomada de decisão são o foco das pesquisas de AEN39.

As pesquisas que abrangem a formação de professores, na terceira categoria, têm dois desdobramentos: (i) o da formação docente inicial, e (ii) o da formação docente continuada. São trabalhos de natureza empírica em que foram priorizados os estudos de caso, as pesquisas de campo e a pesquisa participante. $\mathrm{Na}$ formação docente inicial, as reflexões empreendidas procuram compreender se, no processo formativo, os estudantes de graduação adquirem atributos para o ensino de temas polêmicos relativos ao domínio de conteúdo e à segurança para abordar aspectos éticos e morais (AEN8, AEN30, AEN42). Investigam também o desempenho docente no que contribui para a formação das concepções dos alunos sobre ética e as ações dos meios de divulgação científica (AEN16). No trabalho AEN40 são desenvolvidas ações pedagógicas em um contexto real de poluição gerada pelo plantio de soja em regiões do Mato Grosso, com a finalidade de construir atividades argumentativas a serem utilizadas pelos estudantes de graduação em sua futura atividade docente.

$\mathrm{Na}$ formação docente continuada, o enfoque CTS e a abordagem dos temas controversos em sala de aula foi objeto da pesquisa de AEN2, com o propósito de orientar a definição de parâmetros a serem inseridos nos processos formativos e na atuação dos professores de Ciência. No artigo AEN29 o júri simulado foi explorado, durante um curso de formação de professores de Ciências, sendo indicado como recurso didático para o desenvolvimento das habilidades argumentativas na atuação dos professores em sala de aula. O trabalho AEN35 apresenta uma avaliação de situações de ensino em que do contexto local emergiram questões 
sociocientíficas de debate. Nesse artigo, os autores concluíram que os professores estavam mais motivados ao lidarem com tópicos próximos à sua realidade.

Quatro trabalhos apresentaram a construção ou a investigação sobre recursos didáticos, próxima categoria de análise. São eles: (i) AEN3, com uma pesquisa sobre as fontes aplicadas ao ensino de Genética, de Engenharia Genética e de Biologia Molecular por professores de escolas públicas estaduais, em que se verificou que o acervo de recursos é constituído pelo livro didático e por artigos veiculados na internet, em revistas e jornais; (ii) AEN7, que é referente à elaboração de uma unidade de ensino em termodinâmica, voltada a provocar discussões sobre um tópico em aquecimento global; (iii) AEN9, retrata a construção de um site, por estudantes de licenciatura, para debater os aspectos históricos, geográficos e os argumentos científicos, políticos e sociais emergentes da Transposição do Rio São Francisco no Nordeste do Brasil; e, (iv) AEN37, que expõe a interpretação de textos do livro didático Química e Sociedade, avaliando as contribuições do livro para o estabelecimento de interações discursivas no ensino de questões sociocientíficas. Nesse último trabalho, os autores concluíram, instrumentados pela ferramenta analítica de Mortimer e Scott (2002), que o material didático favoreceu essas interações.

$\mathrm{Na}$ categoria ensaios teóricos, os trabalhos apresentaram diferentes finalidades, como, por exemplo: a construção de atributos para o estudo de exposições em museus de Ciências (AEN13), um levantamento bibliográfico para a composição de uma ferramenta de coleta de dados para a compreensão dos estudos sobre evolução e suas relações com temas sociais (AEN17), a identificação de convergência entre o pensamento de pesquisadores ligados ao movimento de Alfabetização Científica e documentos que se constituem referenciais na temática (AEN19).

Há, também, estudos como os registrados em AEN21 a respeito de casos jurídicos, socioambientais e questões sociocientíficas, com o objetivo futuro de elaborar sequências didáticas. O movimento CTS, a formação de professores e a inserção de questões sociocientíficas são alguns dos aspectos destacados no referencial de AEN26. Os estudos de Mikhail Bakhtin (1895-1975) sobre ética constituem o fundamento teórico das pesquisas realizadas em AEN28 e AEN31 para análise de controvérsias e a tomada de decisão, que decorrem dessas abordagens em sala de aula. As causas naturais e as causas antropogênicas do aquecimento global embasam as reflexões em AEN43, enquanto os autores de AEN46 buscaram estudar a presença de enunciados de ordem sociocientífica nas provas de Ciências da Natureza e suas Tecnologias, do Exame Nacional do Ensino Médio.

Da categoria de ensaios teóricos, em síntese, alguns trabalhos apresentam recortes bem delimitados, com a intenção de elaborar instrumentos para futuras análises; outros têm recortes mais amplos, em que os autores buscaram subsídios para compreender a inserção de questões controversas na Educação em Ciências.

As pesquisas sob a tipologia metaestudos fazem parte do conjunto de trabalhos levantados sobre temas controversos e, apesar de empregarem características metodológicas associadas ao estado do conhecimento realizado neste artigo, apresentam abrangência, foco de análise e recorte temporal diversos aos objetivos da nossa investigação.

O estado da arte realizado pelos autores de AEN10 é sobre as pesquisas de enfoque CTS em que os temas controversos são contemplados. Para isso, os autores investigaram revistas brasileiras de Qualis A e B da área 46 no Portal de Periódicos da Coordenação de Aperfeiçoamento de Pessoal de Nível Superior (CAPES) entre os anos de 2005 e 2008. 
Foram identificados 15 artigos, distribuídos em sete periódicos eletrônicos. Ao contrário do que foi identificado nos trabalhos do ENPEC aqui analisados, o estado da arte realizado em AEN10 revelou que, apesar dos autores daqueles trabalhos considerarem a dimensão discursiva bastante promissora para o estudo da linguagem e do discurso em temas controversos, eles não a utilizaram e empreenderam suas análises nas condições enunciativas por meio da análise de conteúdo.

O estado da arte realizado em AEN25 teve por base de coleta de dados quatro periódicos nacionais e quatro internacionais, entre os anos de 2008 e 2013, quanto à interface entre CTS e as questões sociocientíficas no ensino de Ciências. As autoras optaram por periódicos de estrato A, na base Qualis da área 46, chegando a 73 trabalhos, 52 internacionais e 21 nacionais. Segundo os autores, nos trabalhos nacionais há predomínio do pensamento latino-americano sobre CTS. Os resultados dessa investigação foram comparados e agregados aos obtidos neste artigo.

O estudo inventariante realizado em AEN33 focou os aspectos químicos e ambientais associados a temas controversos no ensino de Ciências nos anais do ENPEC, entre 1997 e 2009. Os trabalhos desse estudo, que apresenta menor abrangência temporal e temática em relação à nossa investigação, foram integrados à análise, no Quadro 4, por sua aproximação com os objetivos desta pesquisa.

Já em relação ao mapeamento de AEN44, associado à perspectiva da Educação Ambiental, verificou-se que os autores identificaram que, nos anais do Encontro de Pesquisa em Educação Ambiental (EPEA), dentre os 398 títulos, apenas um fazia menção à inserção de temas controversos sociocientíficos, entre 2001 e 2011. De acordo com os autores, a temática abordada no artigo foi o uso dos temas controversos no contexto da CTS como estratégia metodológica.

A respeito das considerações elaboradas sobre os 46 trabalhos publicados no ENPEC sob a temática controversa na Educação Científica, optamos por apresentar uma síntese comparativa entre as pesquisas nacionais e as internacionais resultantes desse estado do conhecimento, articulado às respostas das questões orientadoras desta análise, nas considerações finais, logo após a apresentação dos trabalhos internacionais identificados na ERIC.

\section{O perfil das pesquisas internacionais}

As pesquisas identificadas na ERIC foram igualmente codificadas e agrupadas, conforme demonstrado no Quadro 5.

Quadro 5 - Categorização das pesquisas internacionais sobre temas controversos

\begin{tabular}{|l|l|c|}
\hline \multicolumn{1}{|c|}{ Categorias } & \multicolumn{1}{|c|}{ Pesquisas } & \multicolumn{1}{|c|}{$\begin{array}{c}\text { Total por } \\
\text { categoria }\end{array}$} \\
\hline $\begin{array}{l}\text { Metodologias do } \\
\text { ensino }\end{array}$ & $\begin{array}{l}\text { AER1; AER22; AER24; AER34; AER35; AER37; AER44; } \\
\text { AER45; AER50; AER52; AER54; AER58; AER60; AER64; } \\
\text { AER65; AER67; AER70; AER74. }\end{array}$ & 19 pesquisas \\
\hline
\end{tabular}

continua 
Quadro 5 - continuação

\begin{tabular}{|l|l|c|}
\hline \multicolumn{1}{|c|}{ Categorias } & \multicolumn{1}{|c|}{ Pesquisas } & \multicolumn{1}{|c|}{$\begin{array}{c}\text { Total por } \\
\text { categoria }\end{array}$} \\
\hline $\begin{array}{l}\text { Processos de } \\
\text { ensino e de } \\
\text { aprendizagem }\end{array}$ & $\begin{array}{l}\text { AER4; AER6; AER7; AER9; AER12; AER13; AER18; } \\
\text { AER19; AER20; AER21; AER27; AER29; AER31; AER32; } \\
\text { AER33; AER36; AER40; AER42; AER43; AER46; AER47; } \\
\text { AER56; AER57; AER61; AER62; AER63; AER68; AER69; } \\
\text { AER71; AER72; AER73. }\end{array}$ & 30 pesquisas \\
\hline $\begin{array}{l}\text { Formação de } \\
\text { professores }\end{array}$ & $\begin{array}{l}\text { AER8; AER11; AER15; AER16; AER30; AER38; AER39; } \\
\text { AER53; AER59; AER66. }\end{array}$ & 10 pesquisas \\
\hline Recursos didáticos & AER2; AER28. & 2 pesquisas \\
\hline Estudos teóricos & $\begin{array}{l}\text { AER3; AER5; AER10; AER14; AER17; AER23; AER25; } \\
\text { AER26; AER41; AER48; AER49; AER51; AER55. }\end{array}$ & 12 pesquisas \\
\hline
\end{tabular}

Fonte: elaborado pelos autores.

A primeira categoria analisada é a de metodologias do ensino, em que são destacadas as seguintes pesquisas:

(i) AER1, em que os autores, com o intuito de minimizar as dificuldades relatadas por professores do Ensino Médio em inserir, no seu planejamento de aulas, os tópicos controversos, elaboraram roteiros baseados no modelo estudo de caso para o desenvolvimento de unidades em que tópicos controversos sejam entendidos como oportunidades de ensino;

(ii) AER22 e AER74, que estimulam o uso de fontes primárias como estratégia para abordar temas sugeridos por professores como desafiadores, difíceis e que emocionalmente os deixam desconfortáveis em sala de aula;

(iii) AER24, realizada com professores do Ensino Médio de Biologia sobre abordagem baseada em projetos e suas possiblidades para o desenvolvimento cognitivo no ensino e na aprendizagem da evolução;

(iv) AER34, que introduziram tecnologias de realidade aumentada no ensino de energia nuclear e de poluição ambiental com o objetivo de melhorar a aprendizagem de questões sociocientíficas no Ensino Médio;

(v) em relação às tecnologias, ainda cabe mencionar o trabalho AER35 sobre o desenvolvimento de um programa de computador com o intuito de treinar alunos do Ensino Médio em processos de tomada de decisão relacionados à questões ambientais controversas e AER37, sobre a utilização de diálogos eletrônicos de computador para estimular as habilidades de argumentação de estudantes do mesmo nível educacional;

(vi) AER44, que apresenta um modelo de estudo baseado em critérios de avaliação de fontes de pesquisa on-line sobre investigação com células tronco e a sua influência para emissão de pareceres sobre o tema; e

(vii) AER64, sobre a construção de um site deliberativo para abordar os comportamentos e os valores sobre o tema da sustentabilidade individual.

Nessa categoria, ainda, os estudos sobre o processamento centrado em argumentos e contra-argumentos em textos científicos constituiu o foco da pesquisa realizada em AER45. Já 
os estudos realizados em AER70 têm por objeto de investigação as estratégias argumentativas, entre elas as de reconciliação do diálogo, de professores em atividades com questões sociocientíficas. Com a intenção de promover uma aprendizagem mais objetiva sobre os fundamentos científicos relacionados a temas socialmente controversos, os autores de AER60 elaboraram exercícios de metacognição aplicados a alunos do Ensino Médio.

Houve também a inserção de discussões sobre o desenvolvimento de biocombustíveis avançados por meio de um jogo de cartas intitulado Democs e adaptado de uma versão role playing game do Big Bang. O jogo foi apresentado por AER52 como modelo de atividade para professores da Educação Básica com o intuito de inserir essa abordagem metodológica em trabalhos aplicados em sala de aula. A simulação de role playing game também foi considerada no artigo AER54, com estudantes do Ensino Médio. Os autores tiveram a intenção de contribuir para a compreensão da elaboração dos argumentos políticos, econômicos e científicos em torno das mudanças climáticas, assim também em AER58 com estudantes do Ensino Fundamental sobre a temática do uso de animais em pesquisa. Na área da Física, AER50 apresenta a elaboração de um exercício de inquérito guiado com o objetivo de discutir o conceito de Big Bang e introduzir os conhecimentos científicos sobre os gráficos do Hubble com o intuito de aproximar estudantes universitários da visão científica.

Ainda na categoria de metodologias do ensino destacamos o artigo AER65 sobre a arti-

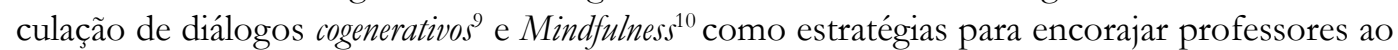
lidarem com discussões complexas e, por vezes, emocionalmente dolorosas. Assim também ocorre com o fórum criado por estudantes de pós-graduação para discutir questões espinhosas em suas vidas acadêmicas e pessoais (AER67). Essas estão entre as primeiras pesquisas identificadas pelo estado do conhecimento que apresentaram características inovadoras para o campo de estudo dos temas controversos, por uma abordagem analítica em que as emoções constituem a centralidade da investigação em situações reais de sala de aula.

A segunda categoria, de processos de ensino e de aprendizagem, foi a que concentrou o maior número de pesquisas. Prevaleceram, nesse grupo, os debates em torno de Ciência e Religião e as pesquisas em biotecnologia com células-tronco. São exemplos: (i) as implicações para a aprendizagem frente às crenças pessoais religiosas e os estudos de evolução (AER4) de professores e alunos (AER6; AER9; AER12); (ii) as atitudes de aceitação e rejeição dos conteúdos científicos (AER20; AER43; AER42; AER62); e, (iii) a necessidade de um ensino de Biologia em classes secundárias e faculdades que favoreça a aprendizagem de conhecimentos biológicos e do método científico estimulados pela participação.

As pesquisas em biotecnologia com células-tronco e alimentos geneticamente modificados embasaram, para um ou para o outro tema, as análises sobre o desenvolvimento da argumentação de estudantes universitários durante o ensino desses tópicos (AER7, AER18, AER72) e o padrão de respostas metacognitivas de alunos do Ensino Fundamental (AER19).

\footnotetext{
${ }^{9}$ Os diálogos cogenerativos são explicados por Tobin e Roth (2005) como uma prática entre os participantes do grupo que têm interesse e dialogam a respeito de incidentes que acontecem em sala de aula e têm o objetivo de melhorar os ambientes de aprendizagem.

${ }^{10}$ Mindfulness significa concentração plena e envolve uma série de exercícios voltados à tomada de consciência sobre si mesmo e sobre as próprias emoções do indivíduo.
} 
Ainda, a respeito dos padrões argumentativos em processos de ensino e de aprendizagem de questões científicas, estão inclusas investigações nos trabalhos AER46 e AER47.

As explicações alternativas de alunos em relação a mudanças climáticas (AER71), o estudo das percepções de estudantes do Ensino Médio acerca de espécies em extinção (AER36) e a autoeficácia comunicativa (AER68) ampliam o número de pesquisas sobre como os alunos articulam o pensamento científico com as diferentes visões de mundo na aprendizagem de tópicos de Ciências Naturais.

O ensino de temáticas controversas sobre corpo, diversidade, saúde pública e saúde sexual dos alunos e os distintos discursos apropriados da aprendizagem informal e formal são o viés dos estudos dos trabalhos AER21, AER27, AER29, AER32, AER57, AER61.

Ainda na categoria processos de ensino e de aprendizagem, chama a atenção um segundo conjunto de trabalhos sobre temáticas controversas que concentram o seu foco de análise nas emoções em sala de aula. Por exemplo, as investigações vinculadas à Psicologia Social e Educacional compõem os trabalhos AER33, AER40, AER63, e, alinhadas à perspectiva dos estudos socioculturais, as investigações de AER31 e AER73. Estas últimas duas revelam indícios de uma emergente mudança no cenário acadêmico em Ciências, com resultados interessantes e metodologias analíticas na pesquisa associadas à instrumentos da neurociência e aos fundamentos teóricos da Microssociologia das Emoções.

Quanto às pesquisas internacionais inseridas na categoria formação de professores, elas apresentaram certo equilíbrio em relação ao número de estudos em formação docente inicial e em formação docente continuada. Na formação docente inicial há uma diversidade de linhas, como, por exemplo: (i) a verificação de protocolos de ensino de assuntos sociocientíficos, aplicados com o objetivo de preparar os futuros professores de Ciências para essa abordagem, abrangendo aspectos epistêmicos sociais e éticos (AER8); (ii) a investigação sobre como estudantes universitários de licenciatura em Ciências Biológicas são questionados em relação aos conhecimentos sobre a teoria da evolução em sala de aula e sobre o seu interesse em ensinar esse tópico na Educação Básica (AER15); e, (iii) a exploração das crenças morais, religiosas, de eficácia e o conhecimento de conteúdo em relação a alimentos transgênicos (AER39). Ainda, uma das pesquisas, caracterizada como trabalho-fronteira, em AER69, oportunizou o debate entre estudantes universitários de licenciaturas sobre disciplinas consideradas, por eles, como não-ciência.

Em termos de intervenções metodológicas na formação docente, os autores de AER53 avaliam um programa de aprendizagem baseada em problemas em um curso de formação inicial de professores para abordagem de tema controverso. Em AER59 temos a proposição de uma sequência didática em que posicionamentos políticos, religiosos e o conhecimento científico são integrados para o estudo da controvérsia cosmológica entre o Big Bang e a teoria do Estado Estacionário.

$\mathrm{Na}$ formação docente continuada, o trabalho AER11 aborda as dificuldades enfrentadas por professores da África do Sul em início de carreira em Ciências Biológicas ao abordarem o ensino da evolução. AER56 também discute a evolução em um estudo que compara a mentalidade de cientistas e de professores. Em viés semelhante, temos o estudo comparativo entre professores de Ciências Judaicas do Ensino Médio e cientistas sobre o tempo geológico e a evolução realizado em AER16, combinando abordagens filosóficas da religião judaica a fim de integrar visões científicas e religiosas. 
Os estudos sobre temas socioambientais envolvendo mudanças climáticas, evolução e idade da Terra estão entre as abordagens de AER30 e de AER38. Os autores propõem, em cursos de formação docente continuada, estratégias de ensino a serem inseridas no planejamento de aulas com o intuito de estimular o debate e promover a alfabetização científica dos alunos. Compõe essa categoria, ainda, a pesquisa realizada em AER66 sobre um curso ofertado a professores em atuação e o uso de oxímetro ${ }^{11}$ como indicador das emoções em sala de aula. A autora do trabalho participava como observadora do projeto desenvolvido no Brooklyn College por Alexakos et al. (2016). Aos poucos ela explica que se sentiu inserida na pesquisa e o seu interesse foi ficando cada vez maior na abordagem de fundo biológico e subjetivo das emoções.

No que tange à categoria de recursos didáticos, duas pesquisas foram identificadas. Elas apresentam materiais elaborados ou analisados com a finalidade de promover situações de divulgação científica, ensino e aprendizagem sobre tópicos controversos do ensino de Ciências. Entre os projetos desenvolvidos, podemos citar: (i) a construção de um site para o ensino da teoria evolução direcionado a estudantes e à população em geral (AER2); e, (ii) a análise sobre a presença de controvérsias do mundo adulto relacionadas à evolução e à origem da vida em livros infantis (AER28).

$\mathrm{Na}$ categoria que reúne os estudos teóricos sobressaem os embates entre Ciência e Religião sob diferentes abordagens. Por exemplo: (i) o trabalho AER17, baseado em Bakhtin (1986) apresenta uma revisão dos aspectos de conteúdo de teor emocional-volitivo e considera que o dialogismo é o caminho para uma aprendizagem holística de áreas muitas vezes entendidas como hostis; (ii) AER41 registra reflexões sobre o conhecimento científico e as crenças religiosas de professores de ensino de Ciências; (iii) AER23 e AER51 versam sobre as dificuldades e oportunidades enfrentadas por professores no ensino da teoria da evolução; (iv) em AER5 os autores incentivam uma abordagem transformadora, baseada na livre troca de ideias, que considera e não ridiculariza diferentes visões de mundo; (v) a relevância das reflexões empreendidas por meio de questões sociocientíficas para a Alfabetização Científica é discutida nos trabalhos AER10 e AER14; (vi) reflexões teóricas sobre estratégias apresentadas por diferentes autores para o ensino de controvérsias e estabelecimento de critérios para seleção do que pode ser ensinado são conduzidos nos trabalhos AER3, AER49 e AER55; (vii) também os temas associados às mudanças climáticas, ao aquecimento global (AER25, AER48); e, (viii) a revisão realizada em AER26 sobre as discussões em torno da nanotecnologia na ciência escolar.

\section{Considerações finais}

Dentre as pesquisas nacionais e internacionais, em resposta às questões norteadoras do estado do conhecimento, verificamos, quanto aos temas controversos abordados com maior

\footnotetext{
${ }^{11}$ As informações registradas nos oxímetros indicam respostas fisiológicas (tais como padrões de respiração e frequência cardíaca) do organismo humano e funcionam como instrumento heurístico para identificar eventos nas situações de ensino. Mais detalhes sobre o uso dos oxímetros em pesquisas qualitativas podem ser consultadas em Saucedo e Pietrocola (2018).
} 
frequência que a grande maioria deles está concentrada em tópicos de ensino da Biologia, enquanto um menor número é da área da Física e da Química.

As pesquisas em biotecnologia, alimentos transgênicos e problemas ambientais são recorrentes no cenário nacional; evolucionismo, origem da vida e criacionismo estão entre os temas controversos mais citados nas pesquisas internacionais, isso acompanhado de temas climáticos. Também ocorre temáticas como (i) as relações entre Ciência, Religião e não-ciência; (ii) o uso de agrotóxicos; (iii) questões étnicas; (iv) doenças sexuais e outras controvérsias em ambos os perfis de pesquisa investigados.

Em relação às reflexões empreendidas imperam as metodologias do ensino, a formação de professores e os processos de ensino e de aprendizagem, mas sempre com destaque para a figura do aluno em relação a do professor. Identificamos que os processos cognitivos relacionados à tomada de decisão, ao desenvolvimento do raciocínio moral, à resolução de problemas, à construção da argumentação, à qualidade do argumento do aluno e do professor, às ações verbais e ao pensamento crítico estão presentes em mais de $90 \%$ dos trabalhos nacionais e internacionais. A natureza da controvérsia foi explorada em poucos trabalhos brasileiros, sendo que, em geral, os temas controversos resultam aplicados em pesquisas para analisar o desenvolvimento da argumentação dos alunos, no contexto CTSA. Alguns dos objetivos almejados nos trabalhos analisados são a formação dos estudantes para o posicionamento frente ao conhecimento científico e tecnológico e o exercício da cidadania e - em menor número - as pesquisas que justificam a sua aplicação para aprendizagem de conteúdos científicos disciplinares.

Em relação aos procedimentos e à tipologia das pesquisas, observamos que a grande maioria das pesquisas nacionais e internacionais, quanto à abordagem é qualitativa, de natureza empírica, ou seja, dedicam-se mais aos estudos aplicados sobre a argumentação dos alunos em sala de aula ou à formação de professores do que a ampliação das reflexões teóricas e conceituais. Quanto aos objetivos, prevalecem as pesquisas exploratórias e explicativas, sendo que os estudos de caso são calcados em pesquisas de campo, etnográficas, participantes e na pesquisa-ação. As pesquisas teóricas são do tipo exploratória, revisões de literatura, documental, sistemática e de mapeamento - metaestudos.

Os instrumentos de coleta mencionados nos trabalhos e artigos são do tipo: questionários, survey, entrevistas, gravações em vídeo, simuladores de jogos interativos, entre outros. Para construção das análises, a dimensão cognitiva foi ressaltada e os pesquisadores seguiram, como, por exemplo, os fundamentos da[o]: análise da narrativa; análise de conteúdo; modelo lógico estruturalista; análise do discurso do sujeito coletivo; análise das interações discursivas; análise do padrão do argumento; análise do grau de sensibilidade moral.

Em síntese, observamos que os estudos sobre temas controversos, relacionados ao estado do conhecimento, buscaram, de algum modo: (i) apresentar possibilidades, recursos, estratégias e meios para o ensino e a aprendizagem de Ciências nos diferentes níveis da Educação Básica e do Ensino Superior; (ii) refletir sobre a formação de professores; (iii) estabelecer relações entre os conhecimentos científico e cotidiano na aprendizagem em Ciências; (iv) avançar em relação à proposição de metodologias inovadoras para pesquisa nesse campo, entre outros aspectos.

Quanto aos níveis educacionais, percebemos que a primeira etapa do Ensino Fundamental apresenta a menor proporção na pesquisa em Educação Científica, assim como a 
formação continuada de professores para essa etapa da Educação Básica, isso em ambos os cenários investigados. Os sujeitos de pesquisa são, em maior número, estudantes do Ensino Médio e de cursos de Graduação nas áreas da Educação e do Ensino, seguidos de professores em atuação ou em formação continuada do Ensino Médio, e uma menor parcela envolve representantes comunitários.

Em termos analíticos, o maior percentual das pesquisas tem o seu foco nos aspectos cognitivos relacionados à elaboração de argumentos, sobretudo no cenário nacional, em detrimento da dimensão emocional. Nos trabalhos internacionais, os construtos teóricos de análise das emoções vieram associados às teorias da Psicologia Social e Educacional e, ainda, uma linha em projeção concentrada em um grupo de pesquisadores, que tem alicerçado as suas bases na Sociologia e na Microssociologia das Emoções.

Destacamos que o estudo da dimensão emocional na vertente da Psicologia Social e Educacional não configura um terreno novo para a área educacional - como exemplo, os trabalhos de Bower (1959), Nias (1996), Hargreaves (1998) e Zembylas (2003), mas, na última década, há um revigorado interesse, sobretudo em relação aos processos de ensino e de aprendizagem. Por outro lado, na área da Educação Científica podemos afirmar que este é um campo recente e, mais especificamente, no estudo dos temas controversos, posto em que a argumentação tem prevalecido como foco de análise na maioria das investigações. Isso indica um desenho de pesquisa a ser integrado também nas investigações brasileiras em Educação Científica, assim como o estudo da formação de docentes para os temas controversos sociocientíficos no Ensino Fundamental, sobretudo nos anos iniciais. Enfatizamos, ainda, a necessidade de pesquisas que melhor definam o conceito e as características do que é compreendido por controvérsias científicas e dos termos a ela associados, para o campo brasileiro da Educação em Ciências.

\section{Referências}

ALEXAKOS, K. et al. Mindfulness and discussing "thorny" issues in the classroom. Cultural Studies of Science Education, Dordrecht, v. 11, n. 3, p. 741-769, set. 2016. DOI: https:// doi.org/10.1007/s11422-015-9718-0.

ASSOCIAÇÃO BRASILEIRA DE NORMAS TÉCNICAS. NBR 6023: informação e documentação: referências: elaboração. Rio de Janeiro: ABNT, 2002.

ASSOCIAÇÃO BRASILEIRA DE PESQUISA EM EDUCAÇÃO EM CIÊNCIAS. Atas dos ENPECs. Disponível em: http://abrapecnet.org.br/wordpress/pt/atas-dos-enpecs/. Acesso em: 17 jun. 2017.

AZEVEDO, R. O. M.; GHEDIN, E.; FORSBERG, M. C. S.; GONZAGA, A. M. O enfoque CTS na formação de professores de Ciências e a abordagem de questões sociocientíficas. In: ENCONTRO NACIONAL DE PESQUISA EM EDUCAÇÃO EM CIÊNCIAS, 9., 2013, Águas de Lindóia. Atas [...]. Águas de Lindóia: ABRAPEC, 2013. p. 1-8. Disponível em: http://www.nutes.ufrj.br/abrapec/ixenpec/atas/resumos/R0325-1.pdf. Acesso em: 28 fev. 2019. 
BAKHTIN, M. Speech genres and other late essays. Austin: University of Texas Press, 1986.

BARDIN, L. Análise de conteúdo. Lisboa: Edições 70, 1995.

BOWER, E. M. The emotionally handicapped child and the school. Exceptional Children, Thousand Oaks, v. 26. n. 1, p. 6-11, 1959.

DUSSO, L. A discussão da controvérsia sociocientífica: uma perspectiva integradora no ensino de ciências. 2015. Tese (Doutorado em Educação Científica e Tecnológica) Universidade Federal de Santa Catarina, Florianópolis, 2015.

EDUCATION RESOURCES INFORMATION CENTER. Disponível em: https:/ / eric. ed.gov/. Acesso em: 21 dez. 2016.

FOUREZ, G. Alfabétisation scientifique et technique: essai sur les finalités de l'enseignement des sciences. Bruxelles: De Boeck Université, 1994.

HARGREAVES, A. The emotional practice of teaching. Teaching and Teacher

Education, Kidlington, v. 14, n. 8, p. 835-854, 1998. DOI: https://doi.org/10.1016/S0742051X(98)00025-0.

KOKSAL, M.; CAKIROGLU, J.; GEBAN, O. The effect of explicit-embedded-reflective instruction on scientific literacy. Croatian Journal of Education, Zagreb, v. 18, n. 2, p. 351390, 2016. Disponível em: https://cje2.ufzg.hr/ojs/CJE_Vol.18_No.2_2016_contents.pdf. Acesso em: 28 fev. 2019.

LEVINSON, R. Towards a theoretical framework for teaching controversial socio-scientific issues. International Journal of Science Education, Abingdon, v. 28, n. 10, p. 1201-1224, 2006. DOI: https://doi.org/10.1080/09500690600560753.

LIMA, A.; MARTINS, I. As interfaces entre a abordagem CTS e as questões sociocientíficas nas pesquisas em Educação em ciências. In: ENCONTRO NACIONAL DE PESQUISA EM EDUCAÇÃO EM CIÊNCIAS, 9., 2013, Águas de Lindoia. Atas [...]. Águas de Lindóia: ABRAPEC, 2013. p. 1-8. Disponível em: http://www.nutes.ufrj.br/abrapec/ixenpec/atas/ resumos/R0173-1.pdf. Acesso em: 28 fev. 2019.

MARTÍNEZ-PEREZ, L. F. Questões sociocientíficas na prática docente: ideologia, autonomia e formação de professores. São Paulo: Editora da Unesp, 2012.

MENDES, M. R. M.; SANTOS, W. L. P. Argumentação em discussões sociocientíficas: estabelecer o contexto, explorar o discurso. In: ENCONTRO NACIONAL DE PESQUISA EM EDUCAÇÃO EM CIÊNCIAS, 8., 2011, Florianópolis. Anais [...]. Florianópolis: ABRAPEC, 2011. p. 1-13. Disponível em: http://abrapecnet.org.br/atas_enpec/viiienpec/ resumos/R0279-1.pdf. Acesso em: 28 fev. 2019.

MORTIMER. E. F.; SCOT'T, P. H. Atividade discursiva nas salas de aula de ciências: uma ferramenta sociocultural para analisar e planejar o ensino. Investigações em Ensino de Ciências, Porto Alegre, v. 7, n. 3, p. 283-306, 2002. 
NIAS, J. Thinking about feeling: the emotions in teaching. Cambridge Journal of Education, Abingdon, v. 26, n. 3, p. 293-306, 1996. DOI: https://doi. org/10.1080/0305764960260301.

ROMANOWSKI, J. P.; ENS, R. T. As pesquisas denominadas do tipo "estado da arte" em educação. Diálogo Educacional, Curitiba, v. 6, n. 19, p. 37-50, set./dez. 2006.

SANTOS, A. Complexidade e transdisciplinaridade em educação: cinco princípios para resgatar o elo perdido. Revista Brasileira de Educação, Rio de Janeiro, v. 13, n. 37, p. 71-83, 2008.

SAUCEDO, K. R. R.; PIETROCOLA, M. As contribuições da oximetria de pulso para o estudo qualitativo das emoções em educação científica. In: SEMINÁRIO INTERNACIONAL DE PESQUISA E ESTUDOS QUALITATIVOS, 5., 2018, Foz do Iguaçu. Anais [...]. Foz do Iguaçu: UFPR, 2018. p. 1-14.

SCHNEIDER-FELICIO, B. V. Apresentação. In: LEVINSON, R. Controvérsias sociocientíficas: aspectos metodológicos para a aproximação entre educação em ciências e educação popular: entrevista com Ralph Levinson. Cadernos CIMEAC, Uberaba, v. 6, n. 1, p. 6-24, 2016. Disponível em: http://seer.uftm.edu.br/revistaeletronica/index.php/cimeac/ article/view/1708/1548. Acesso em: 28 fev. 2019.

SILVA, K. M. A. Questões sociocientíficas e o pensamento complexo: tecituras para o ensino de ciências. 2016. Tese (Doutorado em Educação) - Universidade de Brasília, Brasília, 2016.

SOUSA, P. S.; GEHLEN, S. T. Questões sociocientíficas no ensino de ciências: algumas características de pesquisas brasileiras. Ensaio, Belo Horizonte, v. 19, e. 2569, p. 1- 22, 2017.

TOBIN, K.; ROTH, W.-M. Coteaching/cogenerative dialoguing in an urban science teacher preparation program. In: ROTH, W.-M.; TOBIN, K. (ed.). Teaching together, learning together. New York: Peter Lang, 2005. p. 59-77.

VARGAS, N. J. B.; MARTÍNEZ-PÉREZ, I. F. Enseñanza de las ciências para cidadania en estudiantes de educación media a partir de cuestiones científicas. In: ENCONTRO

NACIONAL DE PESQUISA EM EDUCAÇÃO EM CIÊNCIAS, 8., 2011, Campinas. Atas [...]. Campinas: ABRAPEC, 2011. p. 1-8.

ZEMBYLAS, M. Emotions and teacher identity: a poststructural perspective. Teachers and Teaching: theory and practice, Abingdon, v. 9, n. 3, p. 213-238, 2003. DOI: https://doi. org/10.1080/13540600309378.

Artigo recebido em 04/04/2018. Aceito em 06/08/2018.

Contato: USP, Faculdade de Educação, Av da Universidade, 308, Butantã , São Paulo, SP, 05508 040, Brasil. 
